\title{
Toxicity in Rhesus Monkeys Following Administration of the 8-Aminoquinoline 8-[(4-amino-l-methylbutyl)amino]- 5-(l-hexyloxy)-6-methoxy-4-methylquinoline (WR242511)
}

\author{
Gary A. Rockwood, PhD $a$, Steven M. Duniho, DVM ${ }^{b}$, Crystal M. Briscoe, DVM ${ }^{b}$, \\ Mark B. Gold, DVMc, Kevin R. Armstrong, DVM ${ }^{b}$, Anita V. Moran, BSa, \\ David W. Kahler, BSa, Steven I. Baskin, PharmD, PhDa
}

\begin{abstract}
aAnalytical Toxicology Division, United States Army Medical Research Institute of Chemical Defense, Aberdeen Proving Ground, MD bComparative Medicine Division, United States Army Medical Research Institute of Chemical Defense, Aberdeen Proving Ground, MD cBureau of Medicine and Surgery, United States Navy, Washington, DC
\end{abstract}

\begin{abstract}
Introduction: Many substances that form methemoglobin ( $\mathrm{MHb}$ ) effectively counter cyanide (CN) toxicity. Although MHb formers are generally applied as treatments for $\mathrm{CN}$ poisoning, it has been proposed that a stable, long-acting MHb former could serve as a CN pretreatment. Using this rationale, the 8-aminoquinoline WR242511, a potent long-lasting MHb former in rodents and beagle dogs, was studied in the rhesus monkey for advanced development as a potential CN pretreatment.

Methods: In this study, WR242511 was administered intravenously (IV) in 2 female and 4 male rhesus monkeys in doses of 3.5 and/or $7.0 \mathrm{mg} / \mathrm{kg}$; a single male also received WR242511 orally (PO) at $7.0 \mathrm{mg} / \mathrm{kg}$. Health status and MHb levels were monitored following exposure.

Results: The selected doses of WR242511, which produced significant methemoglobinemia in beagle dogs in earlier studies conducted elsewhere, produced very little $\mathrm{MHb}$ (mean $<2.0 \%$ ) in the rhesus monkey. Furthermore, transient hemoglobinuria was noted approximately 60 minutes postinjection of WR242511 (3.5 or $7.0 \mathrm{mg} / \mathrm{kg}$ ), and 2 lethalities occurred (one IV and one PO) following the $7.0 \mathrm{mg} / \mathrm{kg}$ dose. Myoglobinuria was also observed following the $7.0 \mathrm{mg} / \mathrm{kg}$ dose. Histopathology analyses in the 2 animals that died revealed liver and kidney toxicity, with greater severity in the orally-treated animal.

Conclusions: These data demonstrate direct and/or indirect drug-induced toxicity. It is concluded that WR242511 should not be pursued as a pretreatment for $\mathrm{CN}$ poisoning unless the anti-CN characteristics of this compound can be successfully dissociated from those producing undesirable toxicity.
\end{abstract}

Keywords: 8-aminoquinolines, WR242511, rhesus monkeys, toxicity, pretreatment Funding: Funding for this study was provided by the United States Department of Defense.

Previous presentation: Portions of these data were previously presented as a poster at the US Army Medical Defense Bioscience Review, Hunt Valley, Maryland, in June 2000.

Acknowledgments: The opinions or assertions contained herein are the private views of the authors and are not to be construed as official or as reflecting the views of the Army or the Department of Defense. In conducting this research, the investigators complied with the regulations and standards of the Animal Welfare Act and adhered to the principles of the Guide for the Care and Use of Laboratory Animals (National Research Council, 1996). Photomicrographs were generously provided by Dr. John P. Petrali (USAMRICD). We express our appreciation to the USAMRICD veterinary technicians for their unswerving support. Special thanks to Dr. Robert Christenson (Clinical Chemistry Laboratories, University of Maryland, Baltimore, MD) for expert analyses of the rhesus monkey urine samples.

Corresponding Author: Gary A. Rockwood, PhD, Analytical Toxicology Division, United States Army Medical Research Institute of Chemical Defense, 3100 Ricketts Point Road, MCMR-CDT-N, Aberdeen Proving Ground, MD 21010-5400. Email: gary.a.rockwood@us.army.mil 


\section{INTRODUCTION}

Methemoglobin (MHb) formation is an effective strategy to counter cyanide $(\mathrm{CN})$ toxicity [1-4]. An 8-aminoquinoline, 8-[(4amino-l-methylbutyl)amino]-5-(1-hexyloxy)-6-methoxy-4-methyl quinoline (DL-tartrate), hereafter referred to as WR242511 (Figure 1), was initially studied for its potent antimalarial properties. However, it was discontinued for this purpose due to the significant side effect of MHb formation. In dogs, this compound was shown to have a long half-life and yield stable steady-state $\mathrm{MHb}$ levels; as a result, WR242511 eventually emerged as a leading pretreatment candidate for $\mathrm{CN}$ poisoning [5].

Various animal species, such as mice, rats, sheep, and dogs, have been used to study $\mathrm{MHb}$ formers and $\mathrm{MHb}$ formation, with the beagle dog used particularly often [5-7]. Within the context of the anti-CN features of MHb formers, beagle dogs have been used for the study of numerous classes of $\mathrm{MHb}$ formers, including 8-aminoquinolines, such as WR242511, aminophenones, and aminophenols [5,8-10].

Following preliminary evaluation of WR242511 as a candidate $\mathrm{CN}$ pretreatment in rodents and beagle dogs, the rhesus monkey was selected for the advanced development testing of WR242511 described presently [5,11]. The rhesus monkey models many human responses more accurately than the dog, including responses to various candidate antimalarial compounds [12]. For example, Schmidt and colleagues demonstrated that the rhesus monkey exhibited toxicological as well as neurological sequelae (e.g., equilibrium, coordination, eye muscle movements) following exposure to a series of candidate antimalarial compounds similar to those sequelae reported in humans [13-16]. The rhesus monkey was also the model of choice in an extensive US Army post-WWII-era evaluation of novel antimalarials, including numerous 4 - and 8-aminoquinolines (not including

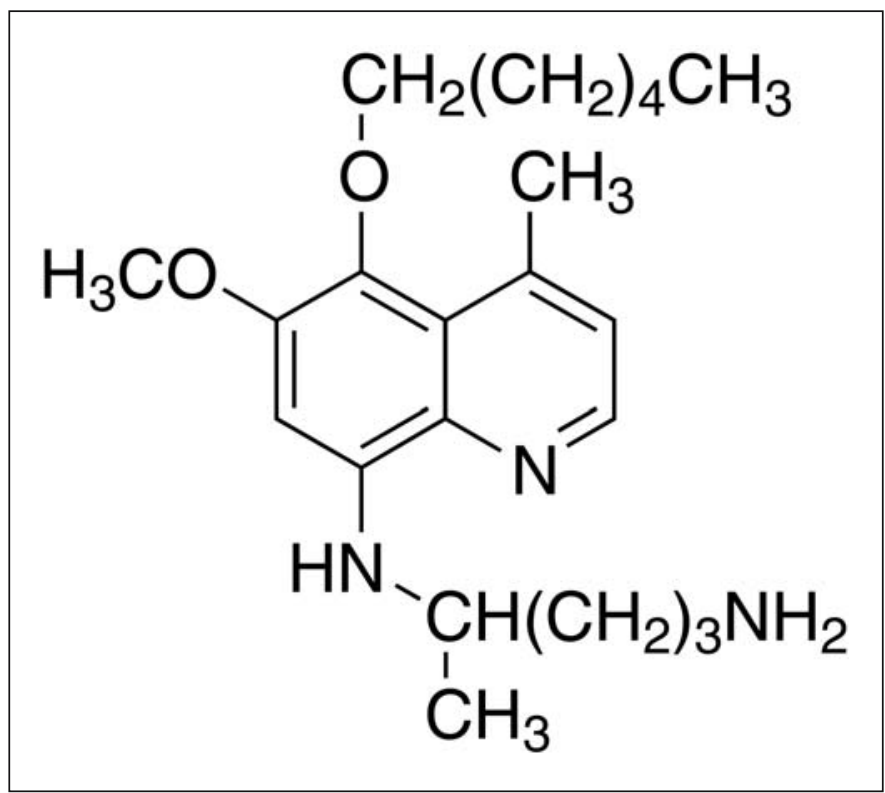

Figure 1: Chemical structure of test compound WR242511.
WR242511, which had not yet been synthesized) $[17,18]$. The rhesus monkey has also shown consistent MHb elevation following exposure to benzocaine as well as the 8-aminoquinoline pamaquine $[17,19]$. Finally, in a related recent preliminary experiment conducted in this laboratory, 5 of the rhesus monkeys reported currently demonstrated consistent $\mathrm{MHb}$ formation following the administration of the prototypical $\mathrm{MHb}$ former $\mathrm{NaNO}_{2}[20,21]$.

In the present study, rhesus monkeys were administered WR242511, and MHb levels and general clinical status were monitored. Little $\mathrm{MHb}$ was formed, but signs of toxicity were observed, as described below. Subsequent experiments were conducted to isolate the source of toxicity, the results of which are presented in a case presentation format.

\section{MATERIALS AND METHODS}

\section{Animals}

Seven specific-pathogen-free rhesus monkeys (Macaca mulatta) served as subjects ( 2 females and 5 males). All animals were healthy and had no history of chronic illness or severe injury. Initial average animal weights were $5.6 \mathrm{~kg}$ and $10.1 \mathrm{~kg}$ for females and males, respectively. Animals were housed individually in sizeappropriate, stainless-steel squeeze-back cages in accordance with the Guide for the Care and Use of Laboratory Animals in an Association for the Assessment and Accreditation of Laboratory Animal Care (AAALAC) International accredited facility [22]. All animals were subject to a minimum of 31 days of quarantine, and were provided with $100 \%$ of caloric requirements and tap water ad libitum [23]. All animals were included in the institute environmental enrichment program. Environmental conditions included a minimum of 10-15 conditioned fresh air changes per hour, a temperature range of $68-72^{\circ} \mathrm{F}$, a relative humidity range of 30-70\%, and a 12-hr light/dark cycle with no twilight. All studies and amendments were approved and monitored by the USAMRICD Institute Animal Care and Use Committee.

\section{Procedures}

Animals were trained to sit in a restraint chair prior to testing. On the day of testing, each animal was tested individually, and remained in the restraint chair for 1 hour postinjection before being returned to its home cage. Drug solutions were prepared fresh on the day prior to or on the day of use. A solution prepared on the day prior to use was kept in a refrigerator until the following morning. Solutions were maintained in an amber glass vial due to chemical light-sensitivity. The production lot of WR242511 used in the present study with rhesus monkeys was the same as that used previously in beagle dogs [24]. WR242511 was initially prepared in polyethylene glycol-200 (PEG200) in a concentration of $7.0 \mathrm{mg} / \mathrm{ml}$. Due to initial experimental results as described below, WR242511 was subsequently prepared in Multisol, in a concentration of $14.0 \mathrm{mg} / \mathrm{ml}$. Multisol is a solvent used for preparing injectable drug solutions at USAMRICD, and similar to the diluent used for commercially available injectable 
diazepam; it is comprised of 48.5\% Millipore water, 40\% propylene glycol, $10 \%$ ethanol and $1.5 \%$ benzyl alcohol. Room temperature injections were administered IV, in a volume of 0.5 $\mathrm{ml} / \mathrm{kg}$, yielding doses of 3.5 and $7.0 \mathrm{mg} / \mathrm{kg}$, using PEG200 and Multisol, respectively, slowly for 2-3 minutes. Doses were selected based on experiments in beagle dogs, as summarized previously [11]. The IV route was selected for ease of administration, since previous reports in beagle dogs demonstrated similar patterns of $\mathrm{MHb}$ formation by IV and PO routes of administration [11,24].

On WR242511 exposure days, venous blood samples were obtained prior to injection, and at 1, 6, 12, and 24 hours postinjection. Subsequent blood sampling occurred daily for as long as 11 days postinjection. Samples were analyzed using the OSM3 Hemoximeter (Radiometer America, Westlake, OH). Full blood chemistry analyses were performed as needed using standard procedures. Urine was collected in a catch tray positioned below the restraint chair.

Also note that some samples of urine from animals described in this report were analyzed by electrophoresis or immunoassay. Urinary hemoglobin was confirmed following both $3.5 \mathrm{mg} / \mathrm{kg}$ and $7.0 \mathrm{mg} / \mathrm{kg}$ WR242511 administration. However, myoglobin was also present in urine following $7.0 \mathrm{mg} / \mathrm{kg}$ WR242511 administration. Although not all urine samples were analyzed, all darkened samples that were analyzed tested positive for hemoglobin or hemoglobin and myoglobin.

\section{RESULTS}

Initially, all animals except one received an IV injection of WR242511 at $3.5 \mathrm{mg} / \mathrm{kg}$ (Table 1). Baseline levels of MHb were all $<1.0 \%$, with a mean of $0.62 \%$.

Darkened (reddish/brown) urine was observed (subsequently, this tested positive for hemoglobinuria), at approximately 60 minutes postinjection. The first incidence of darkened urine was noticed after Animal 3 was exposed to WR242511 and then returned to its home cage. It was not immediately clear whether the fluid was darkened urine or blood from the injection site or

Table 1: Maximum Methemoglobin (MHb) Formation in Six Rhesus Monkeys Following IV Administration of WR242511 (3.5 mg/kg)

\begin{tabular}{lc}
\hline $\begin{array}{l}\text { Animal } \\
1 \text { (female) }\end{array}$ & $\begin{array}{c}\text { Maximum \% MHb Observed } \\
\text { (Time Postinjection) }\end{array}$ \\
\hline 2 (female) & $0.9(72 \mathrm{hr})$ \\
\hline 3 (male) & $3.9(48 \mathrm{hr})$ \\
\hline 4 (male) ${ }^{*}$ & $1.5(96 \mathrm{hr})$ \\
\hline 5 (male) & $1.1(72 \mathrm{hr})$ \\
\hline 6 (male) & $1.0(72 \mathrm{hr})$ \\
\hline${ }^{*}$ Animal received $3.1 \mathrm{mg} / \mathrm{kg}$ due to clogged catheter. & $1.0(48 \mathrm{hr})$ \\
\hline
\end{tabular}

an injury. The animal was then immediately placed back into the restraint chair for clinical examination. No outward clinically apparent external source of blood, injury or irritation was evident, and the animal was returned to its home cage for continuous observation. Subsequent animals also displayed temporary hemoglobinuria during the first urination postinjection ( 60 minutes), but not at later times. It remained unclear whether the hemoglobinuria resulted from the drug, the solvent, or perhaps from undetected irritation due to the length of time the animals remained in the restraint chair ( $\sim 0$ minutes). It is noteworthy that for several days after WR242511 injection, the blood samples drawn for analysis appeared viscous and grossly reddish/brown-tinged.

\section{CASE PRESENTATIONS}

Following observations described above, various procedural parameters were modified to further evaluate the effects of WR242511. Due to the small number of animals available, these results are described below in a case presentation format. See Table 2 for a summary of procedures performed on each animal.

\section{Case 1 (Animal 3)}

To examine the possibility that the hemoglobinuria was due to the diluent and/or the method of restraint, Animal 3 was given an IV injection of PEG200 alone $(0.5 \mathrm{ml} / \mathrm{kg})$. The procedure was conducted 26 days after this same animal had received $3.5 \mathrm{mg} / \mathrm{kg}$ WR242511. Following PEG200 alone, this animal displayed hemoglobinuria at approximately 60 minutes postinjection.

\section{Cases 2 (Animal 5) and 3 (Animal 6)}

In Case 2, Animal 5 was placed in the restraint chair for $\sim 60$ minutes. No darkened urine was produced. This result, combined with that from Case 1, led to the selection of Multisol as an alternate solvent. In Case 3, Animal 6 was injected IV with Multisol $(0.5 \mathrm{ml} / \mathrm{kg})$, and displayed no hemoglobinuria. Therefore, for subsequent tests, Multisol was used as the new solvent for the preparation of WR242511. In addition to changing the solvent, the dose of WR242511 was increased from $3.5 \mathrm{mg} / \mathrm{kg}$ to $7.0 \mathrm{mg} / \mathrm{kg}$, because very little $\mathrm{MHb}$ was produced at the lower dose.

\section{Case 4 (Animals 1 and 4)}

Animals 1 and 4 were each administered WR242511 (7.0 mg/kg in Multisol, IV). Darkened (reddish/brown) urine was observed from each animal, and samples tested positive for both hemoglobinuria and myoglobinuria. As presented in Table 3, very little $\mathrm{MHb}$ was produced in these animals, despite having received the higher dose of WR242511. Furthermore, despite veterinary observation and supportive care, Animal 4 died at $~ 36$ hours postinjection, while Animal 1 survived. A full necropsy was performed on Animal 4; the results are presented below.

\section{Case 5 (Animal 5)}

Several potential reasons for the outcome at $7.0 \mathrm{mg} / \mathrm{kg}$ were addressed, including injection rate and injection route. In studies 
Table 2: Manipulations in Sequential Order

\begin{tabular}{|c|c|c|c|c|c|c|c|c|}
\hline \multirow[t]{2}{*}{ Animal \# } & \multicolumn{8}{|c|}{ Manipulation } \\
\hline & $\begin{array}{c}\text { WR242511 } \\
3.5 \mathrm{mg} / \mathrm{kg}\end{array}$ & $\begin{array}{c}\text { PEG200 } \\
\text { Alone } \\
\text { IV } \\
(+26 \text { d) }\end{array}$ & $\begin{array}{c}\text { Chair } \\
\text { Alone } \\
(+14 \text { d })\end{array}$ & $\begin{array}{c}\text { Multisol } \\
\text { Alone } \\
\text { IV } \\
(+21 \text { d) }\end{array}$ & $\begin{array}{c}\text { WR242511 } \\
7.0 \mathrm{mg} / \mathrm{kg} \\
\text { IV } \\
(+28-46 \mathrm{~d})\end{array}$ & $\begin{array}{l}\text { WR242511 } \\
7.0 \text { mg/kg } \\
\text { IV (Slow } \\
\text { Infusion) } \\
\text { (+120 d) }\end{array}$ & $\begin{array}{c}\text { WR242511 } \\
7.0 \mathrm{mg} / \mathrm{kg} \\
\text { PO }\end{array}$ & $\begin{array}{c}\text { Multisol } \\
\text { Alone } \\
\text { PO } \\
\text { (+212 d) }\end{array}$ \\
\hline 1 & $\sqrt{ }$ & & & & $\sqrt{ }$ & & & \\
\hline 2 & $\sqrt{ }$ & & & & & & & \\
\hline 3 & $\sqrt{ }$ & $\sqrt{ }$ & & & & & & \\
\hline 4 & $\sqrt{ }$ & & & & $\sqrt{ }$ & & & \\
\hline 5 & $\sqrt{ }$ & & $\sqrt{ }$ & & & $\sqrt{ }$ & & \\
\hline 6 & $\sqrt{ }$ & & & $\sqrt{ }$ & & & & $\sqrt{ }$ \\
\hline 7 & & & & & & & $\sqrt{ }$ & \\
\hline
\end{tabular}

Table 3: Summary of Outcome Following Initial IV Administration of $7.0 \mathrm{mg} / \mathrm{kg}$ WR242511 in Two Rhesus Monkeys

\begin{tabular}{lll}
\hline Animal & $\begin{array}{c}\text { Maximum \% MHb } \\
\text { Observed (Time) }\end{array}$ & \multicolumn{1}{c}{ Outcome } \\
\hline 1 & 1.3 (96 hr postinjection) & $\begin{array}{l}\text { Hemoglobinuria and myoglobinuria; } \\
\text { sick, shock, survived (with } \\
\text { veterinary intervention) }\end{array}$ \\
\hline 4 & $1.0(6 \mathrm{hr}$ postinjection) & $\begin{array}{l}\text { Hemoglobinuria and myoglobinuria; } \\
\text { died } \sim 36 \text { hr postinjection } \\
\text { (despite veterinary care) }\end{array}$ \\
\hline
\end{tabular}

described below, WR242511 was administered IV to a single animal over an extended time (60 minutes) and administered via the oral route in a second animal (see Case 6 below).

Animal 5 was anesthetized by a $3.0 \mathrm{mg} / \mathrm{kg}$ intramuscular (IM) injection of tiletamine $(50 \mathrm{mg} / \mathrm{ml}) /$ zolazepam $(50 \mathrm{mg} / \mathrm{ml})$ (Telazol®). WR242511 (7.0 ml/kg, in Multisol, IV) was then slowly administered in a volume of $1.0 \mathrm{ml} / \mathrm{kg}$ across 1 hour, using an infusion pump. A Foley catheter was inserted to allow for urine sampling. No elevated MHb was observed, but hemoglobinuria was very apparent grossly. Analyses revealed hemoglobinuria as well as myoglobinuria. Starting at 5 minutes postinjection, the urine became increasingly darker, and by 60 minutes postinjection, the urine sample was very dark (reddish/brown) with sediment (Figure 2). Subsequent urine samples were clear. This animal did not appear sick and survived with no apparent ill effects (Table 4).

\section{Case 6 (Animal 7)}

This case addressed whether the PO route of administration may be more effective than the IV route in producing $\mathrm{MHb}$ as well as reducing urinary pathology. Animal 7, which had not previously received WR242511, was chemically restrained with Telazol ${ }^{\circledR}(3.0$ $\mathrm{mg} / \mathrm{kg} \mathrm{IM}$ ), and WR242511 (7.0 mg/kg, prepared in Multisol, in a volume of $2.0 \mathrm{ml} / \mathrm{kg}$ ) was administered via a preplaced gastric tube. In this orally exposed animal, no darkened urine was observed, although trace blood was detected in a urine sample obtained at 45 minutes postexposure. A subsequent urine sample taken at 24 hours postexposure tested positive for hemoglobinuria. In addition, urine samples obtained at various times during the 24-hour postexposure period were all positive for slight myoglobinuria. This animal showed no appreciable MHb elevation (baseline, 0.5\%; maximum MHb observed postinjection, $0.9 \%$ ). Vomiting was observed at 24,36 , and 48 hours postexposure. The attending veterinarian monitored the animal and noted no significant clinical findings other than vomiting. The animal demonstrated normal postural repertoire, and appeared alert, responsive, well hydrated, and healthy, aside from the vomiting. By 96 hours postexposure, the animal's physical condition deteriorated, as it became depressed and dehydrated. The attending veterinarian administered IV fluids and supportive care; however, the animal died approximately 2 hours later. A complete necropsy was performed (see below). As a result of this unexpected death, a solvent/procedure control test was conducted, described below in Case 7.

\section{Case 7 (Animal 6)}

Multisol alone was administered PO to Animal 6, under conditions identical to those present during the WR242511 oral exposure. No ill effects were noted in this animal (see Table 4).

\section{Pathology}

Following their deaths, Animals 4 and 7 were each submitted for complete postmortem examination. Representative samples of 


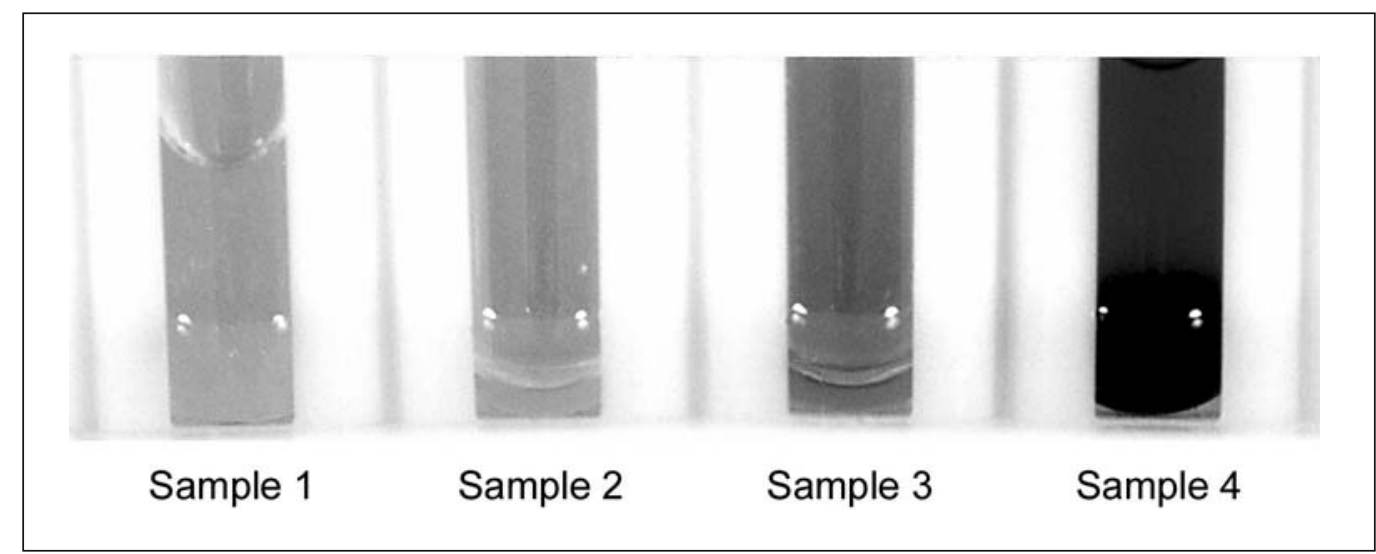

Figure 2: Serial urine samples during and following a 60-minute slow IV infusion of WR242511 $(7.0 \mathrm{mg} / \mathrm{kg})$. Sample 1: baseline prior to infusion. Sample 2: 40 minutes after the start of infusion. Sample 3: 5 minutes postinfusion. Sample 4: 60 minutes postinfusion. These serial samples were obtained from Animal 5.

\begin{tabular}{|c|c|c|c|c|}
\hline Animal & Route & Treatment & Dose & Outcome \\
\hline 5 & IV (slow) & WR242511 & $7.0 \mathrm{mg} / \mathrm{kg}$ & Hemoglobinuria, myoglobinuria \\
\hline 7 & $\mathrm{PO}$ & WR242511 & $7.0 \mathrm{mg} / \mathrm{kg}$ & $\begin{array}{l}\text { Vomited; slight myoglobinuria; } \\
\text { hemoglobinuria; died - } 98 \mathrm{hr} \\
\text { postexposure }\end{array}$ \\
\hline 6 & $\mathrm{PO}$ & Multisol & - & No ill effects \\
\hline
\end{tabular}

tissues were collected during the examination. Tissues were fixed in $10 \%$ neutral buffered formalin, embedded in paraffin, sectioned at $5.0 \mu \mathrm{m}$, and stained with hematoxylin and eosin (H\&E).

\section{Gross necropsy findings}

In Animal 4, there were no significant gross lesions except that the lungs appeared wet. In Animal 7, there were multiple organ ecchymoses and hemorrhages involving the epicardial surface of the heart, pericardium, internal thorax, and pancreas. The liver was diffusely dark red with a light-colored reticulated pattern that accentuated hepatic lobules (Figure 3).

\section{Microscopic findings}

In Animal 4, the lungs were diffusely and severely expanded by edema and fibrinous exudates. Multifocally, several pulmonary arterioles contained fibrin thrombi (Figure 4). The liver was diffusely congested and exhibited diffuse, moderate hepatocellular vacuolar degeneration. There was mild, multifocal renal tubular epithelial degeneration and congestion. There was multifocal, mild, subacute myocarditis with a focal area of epicardial hemorrhage. In Animal 7, the hepatic architecture was completely disrupted by sublobular necrosis and diffuse hemorrhage with moderate to severe periportal hepatocellular degeneration (Figure 5). There was moderate to severe degeneration and necrosis of tubular renal epithelium and, multifocally, tubules contained cellular, granular or hemoglobin casts (Figure 6). The presence of intratubular hemoglobin was confirmed with special stains. There was diffuse, acute necrosis of the adrenal zona reticularis. There was also multifocal, mild acute hemorrhage present in the periductular regions of the pancreas, meninges, pericardium, periesophageal fibroadipose tissue, and thymus. The hemorrhage in the pericardium was accompanied, multifocally, by intra-arteriolar fibin thrombi.

\section{Pathology interpretation}

The histopathological results strongly suggest that the lesions in the liver and kidney of both animals were the result of acute toxicity, although of varying degrees. The presence of hemorrhage in multiple organs from Animal 7 is compatible with a generalized coagulation disorder most likely secondary to severe liver dysfunction. Necrosis of the zona reticularis in the adrenal gland of Animal 7 is also consistent with an acute toxic insult. The presence of hemoglobin in urine and renal tubules indicates intravascular red blood cell damage (hemolysis). The exact mechanism of hemolysis is unknown. The pulmonary lesions in Animal 4 reflect 


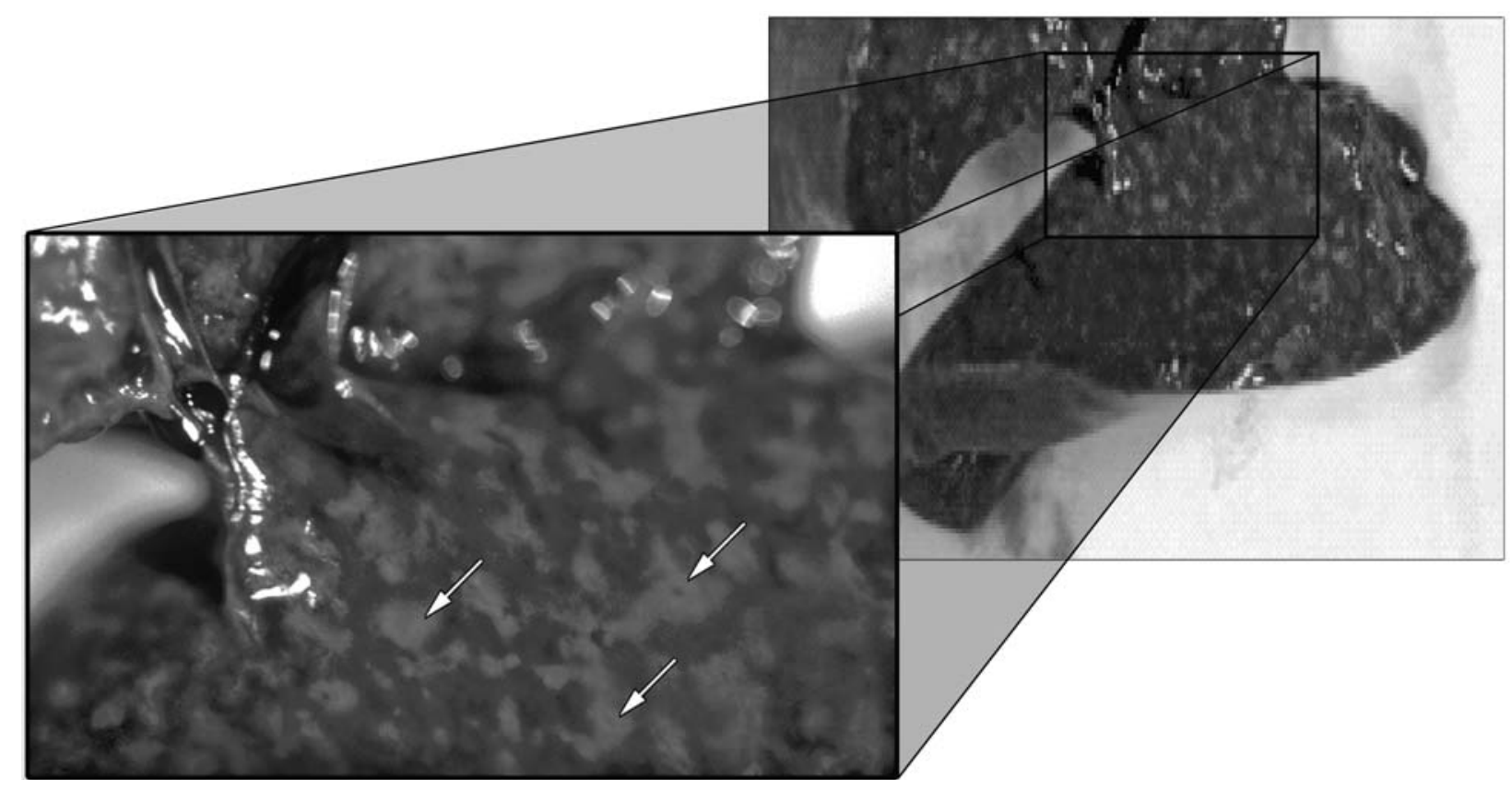

Figure 3: Liver with diffuse congestion and reticular pattern (Animal 7).

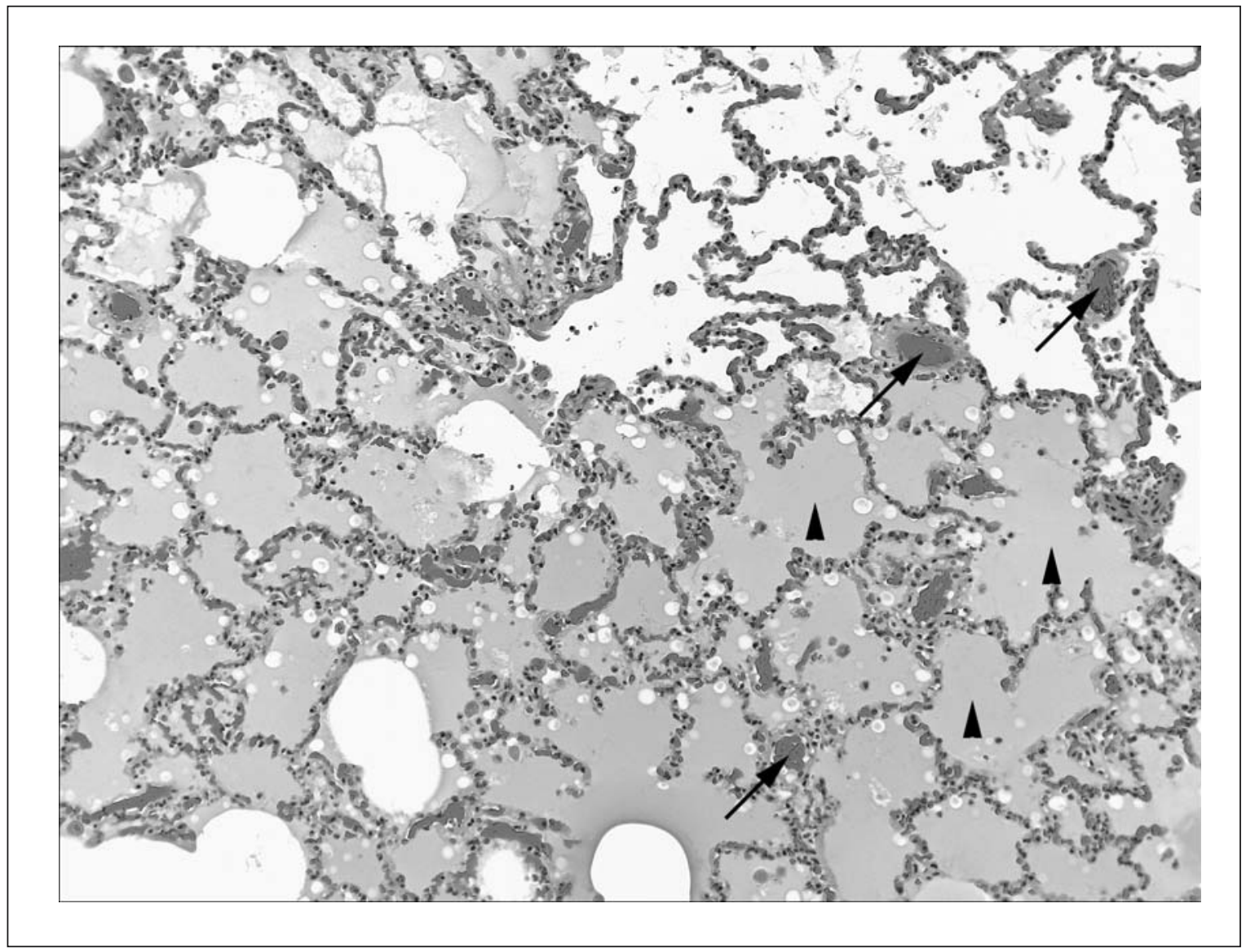

Figure 4: Lung with moderate alveolar edema (arrowheads) and fibrin thrombus (arrows) (x100) (Animal 4). 


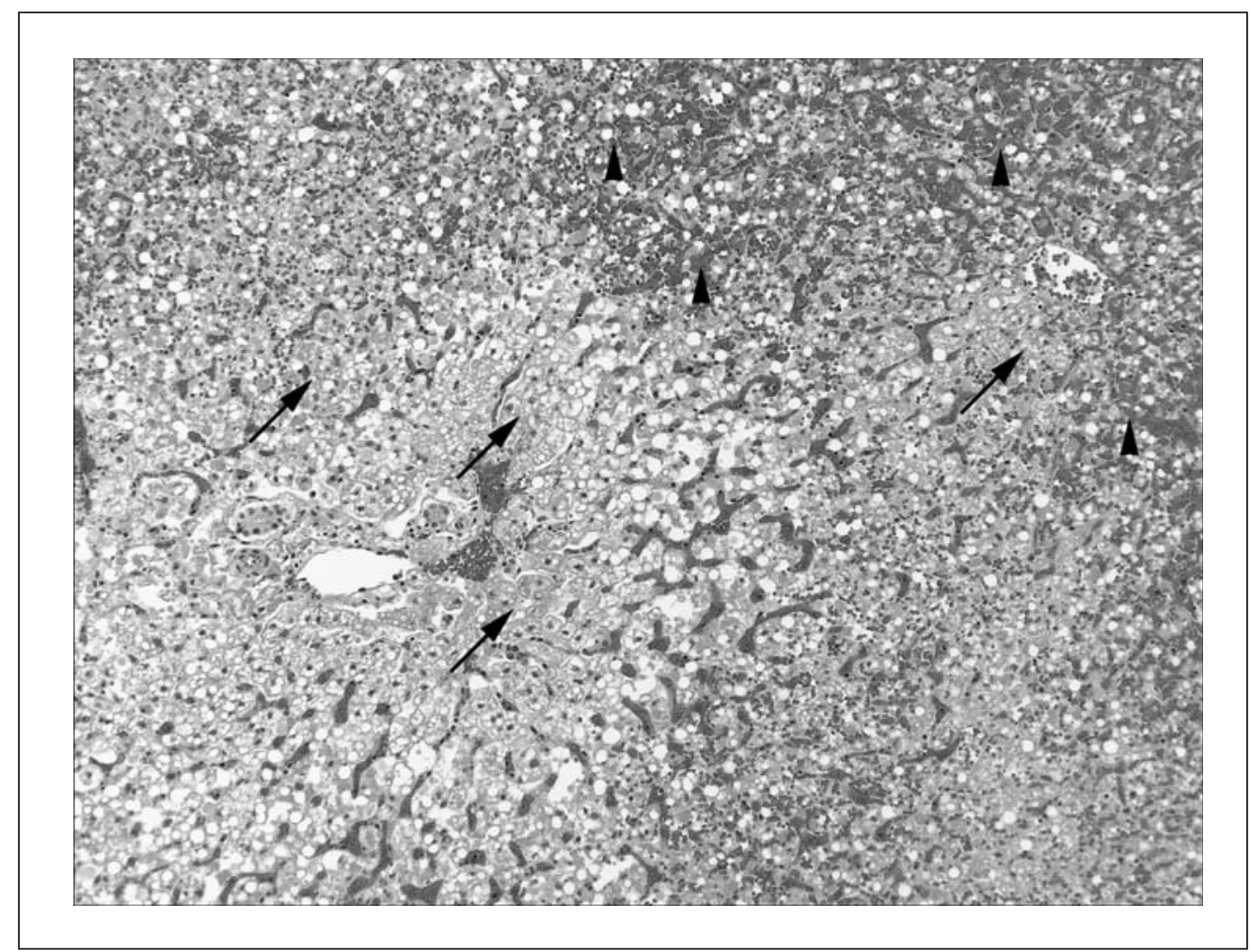

Figure 5: Liver with submassive necrosis (arrows) and hemorrhage (arrowheads) (x100) (Animal 7).

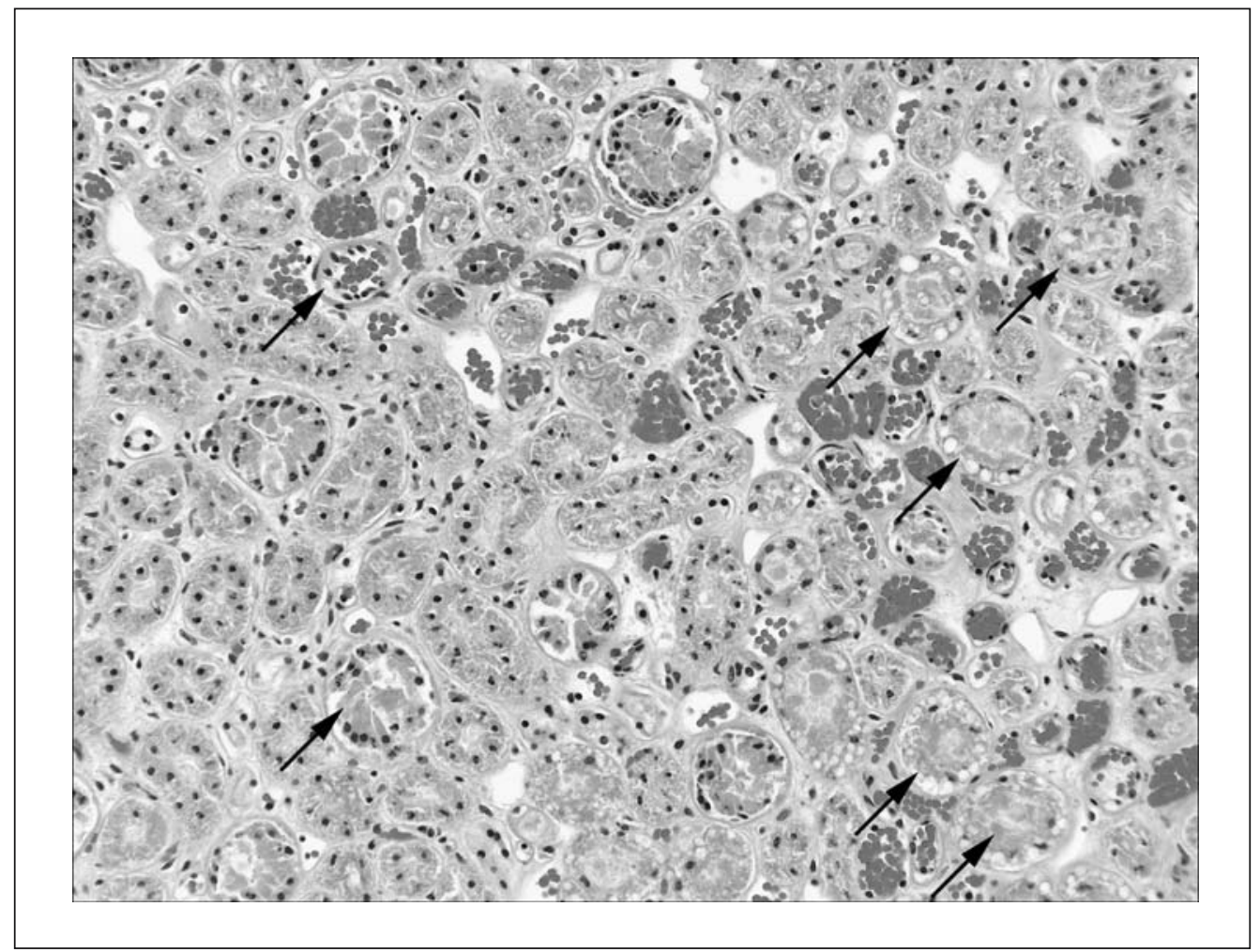

Figure 6: Kidney with tubular epithelial degeneration and necrosis, and intratubular cellular, granular, or hemoglobin casts (x100) (Animal 7). 
severe extravascular leakage of proteinaceous fluid and fibrin thrombosis. In light of the other lesions in these 2 animals, it is speculated that this too may be the result of a toxic effect on the pulmonary microvasculature. Although the acute myocardial hemorrhage appears to be related to the toxic events in both animals, the myocarditis may represent an older lesion. The different routes of administration (PO vs. IV) most likely explain the difference in target organs and severity of lesions in these 2 animals. The exact mechanism of toxic injury, whether an effect of the compound itself or a biotransformed metabolite, is unknown at this time.

\section{DISCUSSION}

WR242511 produced little or no elevation of MHb levels in rhesus monkeys, a species previously shown to respond to a variety of other MHb formers [10,13,19-21]. Furthermore, toxicity was observed in the WR242511-exposed rhesus monkeys, ranging from hemoglobinuria (at both 3.5 and $7.0 \mathrm{mg} / \mathrm{kg}$ ) and myoglobinuria (at $7.0 \mathrm{mg} / \mathrm{kg}$ ) to liver, lung, and kidney damage, with death resulting in the most severely affected animals. Oxyhemoglobin levels also decreased following WR242511 [20]; cyanosis, however, was not apparent. Direct or indirect toxicity associated with WR242511 seems the most plausible explanation of our observations. There are several other possible explanations for these findings in the rhesus monkey exposed to WR242511, such as the solvent, chairing procedure, route of drug administration, drug dosage, drug purity, and animal species. Although these alternative explanations are discussed below, none appears to have contributed significantly to the untoward results observed in this study.

\section{Solvent}

When WR242511 (3.5 mg/kg IV) was first administered with PEG200 as the solvent, hemoglobinuria was observed. Because hemoglobinuria was also observed in a single rhesus that received PEG200 alone, this solvent was replaced with Multisol. Multisol alone did not result in hemoglobinuria.

However, when WR242511 prepared with Multisol also resulted in hemoglobinuria, WR242511 and not the solvent was further scrutinized. The particular animal administered PEG200 alone had received WR242511 (3.5 mg/kg) approximately 26 days prior to the PEG200-alone exposure. A portion of the WR242511 from the original exposure may have remained sequestered in the animal, and when PEG200 alone was administered to this animal 26 days later, the sequestered drug was redistributed and produced the observed hemoglobinuria. It is noteworthy that under certain experimental conditions, the level and pattern of $\mathrm{MHb}$ formation following the administration of compounds such as phenones and $\mathrm{NaNO}_{2}$ is route dependent $[4,25]$.

\section{Chairing procedure}

Chairing a rhesus monkey for 1 hour (or slightly longer) was also examined as a possible explanation for the hemoglobinuria. This, however, was ruled out when a chair-restraint control animal did not exhibit tissue irritation or discolored urine, as would not be expected from this common laboratory practice.

\section{Rate of IV injection}

WR242511 was initially administered IV across 2-3 minutes. In the slow-infusion (1-hour) experiment, the animal survived, but did exhibit both hemoglobinuria and myoglobinuria.

\section{Route of administration}

WR242511 was initially administered IV in rhesus monkeys. All animals exhibited hemoglobinuria; those administered the higher dose $(7.0 \mathrm{mg} / \mathrm{kg})$ also exhibited myoglobinuria. One animal that received $7.0 \mathrm{mg} / \mathrm{kg}$ died; a second animal that received this dose became ill, but recovered. When a single rhesus monkey was dosed with $7.0 \mathrm{mg} / \mathrm{kg} \mathrm{PO}$, the animal died. It is noteworthy that in the beagle dog, methemoglobinemia following WR242511 was independent of route of administration (IV or PO) [24].

\section{Drug dose selection}

The doses used in this study are consistent with doses used previously in the beagle dog [24].

\section{Drug purity}

Several sample WR242511 solutions, as well as samples of the solvents, were evaluated using mass spectrometry to determine whether the observed effects in rhesus monkeys were due to a degraded or tainted drug sample. The test results were consistent with the chemical composition of WR242511 and showed no indication of contamination. Furthermore, sample WR242511 solutions, as well as samples of the solvents, were submitted to pyrogen testing by the Celsis Laboratory Group (Edison, NJ). The samples appeared pyrogen-free, although very low pyrogen levels, below the threshold of detection, cannot be ruled out. It appears unlikely, however, that pyrogen contamination (in the drug or solvents) can explain the toxicity observed in the rhesus monkeys.

\section{Species}

Studies in dogs demonstrated generally transient toxicity following WR242511 exposure [24]. In a study conducted by Johnson in 1987, 1 of 2 beagle dogs died after receiving oral WR242511 (in gelatin capsules) at $7.024 \mathrm{mg} / \mathrm{kg}$ once daily for 4 consecutive days [26]. Unfortunately, cause of death was not determined. Regarding this 8-aminoquinoline, it was concluded that, "Although WR 242,511 is a potent methemoglobin inducer, its associated toxicity, at least at the dose levels used in this study, would preclude its use as a cyanide antidote" [26] (p. 42). Though MHb levels were elevated in these animals, it is unlikely that methemoglobinemia precipitated the death, since MHb levels were decreasing (i.e., MHb levels were $32 \%$ and 29\% 3 and 2 days prior to death, respectively). At specific times following the last day of drug administration, both animals receiving the multiple dosing regimen of WR242511 described above exhibited decreased activity (days 2-9), anorexia (days 2-9), diarrhea (days 3-4), and no stools 
(days 5-9). Furthermore, in the animal that died, considerable increases were observed in alanine aminotransferase (ALT), aspartate aminotransferase (AST) and alkaline phosphatase (SAP) at 72 hours, 5 days, and 12 days after WR242511 administration, compared with baseline. These likely correspond to "hepatic cellular degeneration, skeletal and cardiac degeneration and/or obstructive icterus in dogs for ALT, AST and/or SAP, respectively. These increases were most likely a direct result of WR 242,511 administration" (p. 33). Other dogs reported in this study received a single oral dose of WR242511 at 7.024 or $14.048 \mathrm{mg} / \mathrm{kg}$ ( 2 dogs per dose). One subject that received $14.048 \mathrm{mg} / \mathrm{kg}$ showed similar changes in ALT, AST and SAP at 72 hours after drug administration. No other significant changes were noted in these other animals, aside from time-dependent increases in MHb levels. Interestingly levels of enzymes important for species sensitivity and responsiveness to MHb-forming drugs, such as glucose-6-phosphate dehydrogenase and methemoglobin reductase, are similar in the rhesus monkey and in humans $[27,28]$.

As described above, toxicity following exposure to WR242511 is not unique to the rhesus monkey. Levine and colleagues reported a pattern of toxicity in rats and dogs following oral WR242511 [8]. Furthermore, although generally effective in the beagle dog as an MHb former, toxicity of WR242511 was observed in this species as well. Some of these toxic effects are similar to that observed presently in the rhesus monkey. For example, hematuria was noted for the first day after drug administration in beagle dogs that received $7.0 \mathrm{mg} / \mathrm{kg}$ WR242511 IV prepared in PEG200 [24]. In a related study, beagle dogs that received WR242511 either IV (3.5 or $7.0 \mathrm{mg} / \mathrm{kg}$, prepared in PEG200) or PO (7.0 mg/kg, in gelatin capsules) showed hemolysis, which cleared within 48 hours; gross hemoglobinuria, however, was not observed [5]. In addition, one animal vomited after receiving the oral dose of WR242511 [5].

\section{CONCLUSIONS}

In an advanced model using rhesus monkeys designed to evaluate the safety of a potential anti-CN pretreatment (WR242511), a variety of toxic responses were observed. Although the severity of toxicity was more pronounced in the rhesus monkey, toxic responses have also been seen in several other species exposed to WR242511, across different routes of administration. Therefore, unless the anti-CN characteristics of this compound can be successfully dissociated from those that produce undesirable toxicity, WR242511 should not be pursued as a pretreatment for $\mathrm{CN}$ poisoning.

\section{REFERENCES}

1. Baskin SI, Fricke RF. The pharmacology of p-aminopropiophenone in the detoxification of cyanide. Drug Reviews 1992; 10:358-375.

2. Baskin SI, Rockwood GA. Neurotoxicological and behavioral effects of cyanide and its potential therapies. Mil Psychol 2002;14:159-177.
3. Chen KK, Rose CL. Nitrite and thiosulfate therapy in cyanide poisoning. JAMA 1952;149:113-119.

4. Rockwood GA, Baskin SI, Romano JA Jr, Murrow ML, Preville JA, Lee RB, et al. Comparison of hematologic consequences and efficacy of p-aminophenones in mice. Environ Toxicol Pharmacol 1999;7:237-252.

5. Marino MT, Peggins JO, Brown LD, Urquart MR, Brewer TG. Pharmacokinetics and kinetic-dynamic modeling of an 8-aminoquinoline candidate anticyanide and antimalarial drug (WR242511). Drug Metab Dispos 1994;22:358-366.

6 . Bright JE, Marrs TC. Kinetics of methaemoglobin production (2). Kinetics of the cyanide antidote p-aminopropiophenone during oral administration. Hum Toxicol 1986;5:303-307.

7. Marrs TC, Bright JE. Kinetics of methaemoglobin production (1). Kinetics of methaemoglobinemia induced by the cyanide antidotes p-aminopropiophenone,p-hydroxyaminopropiophenone or p-dimethylaminophenol after intravenous administration. Hum Toxicol 1986;5:295-301.

8. Levine BS, Wheeler CW, Tomlinson MJ. Acute and subchronic oral toxicity of the anticyanide drug WR242511 tartrate. Toxicologist 1996;30:106-107.

9. Bright JE, Woodman AC, Marrs TC, Wood SG. Sex differences in the production of methemoglobinemia by 4-aminopropiophenone. Xenobiotica 1987;17:79-83.

10. Bright JE, Marrs TC. A model for the induction of moderate levels of methaemoglobinemia in man using 4-dimethylaminophenol. Arch Toxicol 1982;50:57-64.

11. Transition Information Paper. WR242511 and WR269410—methemoglobin-formers as cyanide prophylactics for the soldier. Walter Reed Army Institute of Research, Washington, DC, U.S. Army Medical Research Institute of Chemical Defense, APG, MD, and U.S. Army Medical Research and Materiel Command Research Area V, Medical Chemical Defense Research Program, Frederick, MD, 1994.

12. Smith CC. Predicting drug metabolism pathways in man. In: Vagrborg, H, ed. Use of nonhuman primates in drug evaluation. Austin: University of Texas Press; 1968. pp. 470-479.

13. Blanchard KC, Schmidt LH. Chemical series of potential interest. In: Wiselogle FY, ed. A Survey of Antimalarial Drugs, Ann Arbor: JW Edwards, Vol 1; 1946. pp.73-175.

14. Schmidt LH. Relationships between chemical structures of 8-aminoquinolines and their capacities for radical cure of infections with plasmodium cynomolgi in rhesus monkeys. Antimicrob Agents Chemother 1983;24: 615-652.

15. Schmidt LH, Fradkin R, Vaughn D, Rasco J. Radical cure of infections with plasmodium cynomolgi: a function of total 8-aminoquinoline dose. Am J Trop Med Hyg 1977;26:1116-1128.

16. Schmidt IG, Schmidt LH. Neurotoxicity of the 8-aminoquinolines. J Comp Neurol 1949;91:337-368.

17. Moe GK, Peralta V, Seevers MH. Central impairment of sympathetic reflexes by 8-aminoquinolines. J Pharmacol Exp Ther 1949;95:407-414.

18. Wiselogle FY. A survey of antimalarial drugs, Vol 1, Ann Arbor: J.W. Edwards; 1949. 
19. Martin DG, Watson CE, Gold MB, Woodard CL, Baskin SI. Topical anesthetic-induced methemoglobinemia and sulfhemoglobinemia in macaques: a comparison of benzocaine and lidocaine. J Appl Toxicol 1995;15:153-158.

20. Rockwood GA, Duniho SI, Briscoe CM, Gold MB, Armstrong KR, Shih ML, et al. The effects of WR242511 in rhesus monkeys. USAMRICD-TR-00-10. U.S. Army Medical Research Institute of Chemical Defense, Aberdeen Proving Ground, MD. A385196;2000.

21. Rockwood GA, Gold MB, Finger AV, Baskin SI. The effects of sodium nitrite on methemoglobin formation in nonhuman primates. Toxicologist 1999;48:373-374.

22. National Research Council. Guide for the care and use of laboratory animals. Washington: National Academy Press, 1996.
23. National Research Council. Nutrient requirements of nonhuman primates. Washington: National Academy of Sciences, 1978.

24. Noker PE. Single dose iv and oral pharmacokinetics, bioavailability and metabolism study of WR242511 in dogs. Final Report, Contract: DAMD 17-93-C-3004, 1994.

25. Vick, JA, Froehlich H. Treatment of cyanide poisoning. Mil Med 1991; 156:330-339.

26. Johnson, WD. Effects of methemoglobin versus potassium cyanide intoxication. Final Report, Contract: DAMD17-83-C3083. AD-B122 370, 1987.

27. Eng L-IL. Glucose-6-phosphate dehydrogenase activity in the red blood cells of monkeys. Nature 1962;195:1110.

28. Rockwood GA, Armstrong KR, Baskin SI. Species comparison of methemoglobin reductase. Exp Biol Med 2003;228:79-83. 